\title{
Insulin Resistance Provides the Connection Between Hepatitis C Virus and Diabetes
}

\author{
Sher Zaman Safi ${ }^{1,} ;$ Humaira Shah ${ }^{1}$; Gracie Ong Siok Yan ${ }^{2}$; Rajes Qvist \\ ${ }^{1}$ Department of Medicine, Faculty of Medicine, University of Malaya, Kuala Lumpur, Malaysia \\ ${ }^{2}$ Department of Anesthesiology, Faculty of Medicine, University of Malaya, Kuala Lumpur, Malaysia \\ ${ }^{*}$ Corresponding Author: Sher Zaman Safi, Department of Medicine, Faculty of Medicine, University of Malaya, 50603 Kuala Lumpur, Malaysia. Tel: 03-79674750, Fax: 03-79568841, \\ E-mail:safi.nust@yahoo.com
}

Received: September 27, 2014; Accepted: December 8, 2014

Keywords:Hepacivirus; Diabetes Mellitus; Insulin; Insulin Resistance

\section{Insulin Resistance as a Bridge Between Hepatitis C Virus and Diabetes}

Both diabetes and hepatitis $\mathrm{C}$ virus (HCV) infection are severe health problems worldwide, especially in the developing countries $(1,2)$. A range of extrahepatic (EH) manifestations such as arthralgias, thyroiditis and diabetes are linked with HCV infections (3-5). Studies have shown that patients infected with hepatitis $\mathrm{C}$ virus (HCV) have more glucose intolerance than the general population. According to a report, up to one-third of patients with chronic liver disease caused by hepatitis $C$ virus (HCV) infection develop type II diabetes mellitus (6). It is well documented that the levels of reactive oxygen species (ROS) are higher in both diabetic and HCV infected patients $(7,8)$. This potential synergism of HCV and diabetes is attributed to the multifaceted interactions between HCV and glucose metabolism. In our previous study, we showed that HCV may also cause hepatic steatosis, even though the clinical impact of viral steatosis is still debated (9). Among all factors, insulin resistance seems to be a vital feature of the pathogenesis of HCVinduced glucose intolerance. Several mechanisms may account for the development of insulin resistance in patients with chronic HCV infection. For instance there is evidence for a triangular interaction between insulin resistance, steatosis and inflammatory cytokines (Figure 1). This triangle of interactions means that insulin resistance associated with diabetes or $\mathrm{HCV}$, can promote fatty liver (steatosis) and fat accumulation may in turn promote insulin resistance and inflammation. HCV promotes dysfunction of insulin signaling pathways via several distinct mechanisms. One of our recent studies on HIT-T15 cells, cultured under hyperglycemic conditions demonstrated increased insulin resistance with a signifi- cant increase in the levels of MAPK, NF- $\mathrm{B}$ and IRS-1 serine phosphorylation (ser307) and decreased Akt and insulin contents (10). Similarly, studies demonstrated that HCV infection also induces insulin resistance through impairment of IRS-1 and AKT, in particular, increasing the IRS-1 phosphorylation at serine residues and decreasing it at tyrosine residues $(11,12)$. Furthermore, HCV up-regulates the expression of suppressors of cytokine signaling 3 (SOCS3) and tumor necrosis factor- $\alpha$ (TNF- $\alpha$ ), while down-regulates peroxisome proliferator-activated receptors gamma (PPAR $\gamma)(13,14)$. HCV genotype 1 usually affects IRS-1 through SOCS-3 mediated ubiquitinylation, while HCV genotype 3 diminishes IRS-1 via enhanced expression of SOCS-7 $(14,15)$.

The association between HCV and diabetes was initially perceived as a non-specific consequence of hepatic inflammation. To verify this view, Shintani et al. (16) conducted a study by expressing HCV core protein in transgenic mice. HCV core protein resulted hepatic insulin resistance in the transgenic mice; however, HCV core protein-induced insulin resistance was reversed by administration of antibodies against TNF- $\alpha$. Due to enhanced levels of interleukin (IL)-1, interleukin (IL)-6, Leptin and tumor necrosis factor (TNF)- $\alpha$ and reduced levels of adiponectin, chronic inflammation plays a substantial role in the development of insulin resistance. These inflammatory cytokines stimulate the inflammatory mediator I $\mathrm{B}$ kinase $\beta$ (IKK $\beta$ ) and IKK $\beta$ induces the proteasomal degradation of anti-inflammatory inhibitor of $\mathrm{NF \kappa B}(\mathrm{I} \kappa \mathrm{B})$ at serine 32 and 36 , allowing nuclear translocation of the downstream effector molecule $\mathrm{NF} \kappa \mathrm{B}$ to promote insulin resistance (17-19). The same happened in our study (unpublished) where hyperglycemia increased phosphorylation of IкB at serine 32 and 36 in Human umbilical vein endothelial cells (HUVECs).

Copyright (C) 2015, Kowsar Corp. This is an open-access article distributed under the terms of the Creative Commons Attribution-NonCommercial 4.0 International License (http://creativecommons.org/licenses/by-nc/4.0/) which permits copy and redistribute the material just in noncommercial usages, provided the original work is properly cited. 


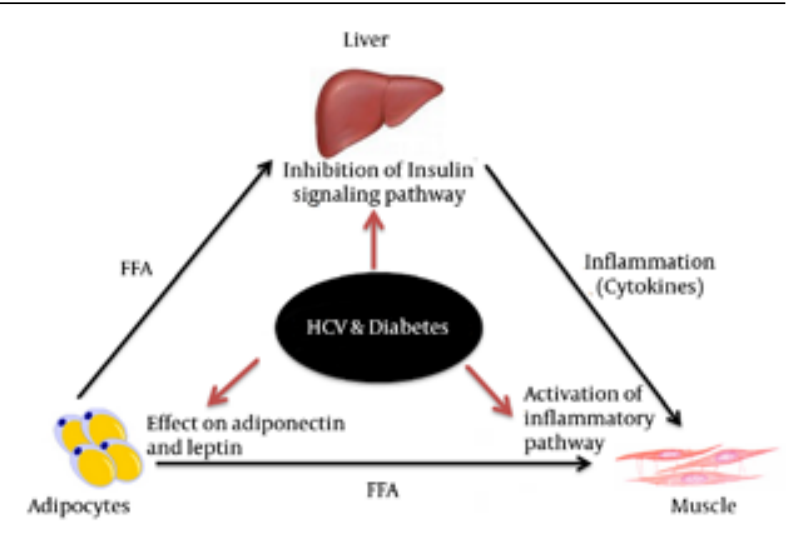

Figure 1. Schematic Presentation of the Association of HCV and Diabetes and the Pathways and Factors Which Mediate Insulin Resistance Synergistically

\section{Risk Factors}

Studies indicated that family history of diabetes, obesity and severe liver fibrosis are the key risk factors for developing both HCV and diabetes concomitantly. Atherosclerosis patents have been reported at greater risk for developing HCV and diabetes. Literature also showed that interferon therapy might have some implications in the development of diabetes in HCV infected patients; however, this association is quite rare and cannot be regarded as potential risk factors. Furthermore, insulin sensitivity in non-diabetic HCV patients has revealed significant association with histological activity index, serum aspartate aminotransferase and the degree of fibrosis (20).

\section{Authors' Contributions}

Sher Zaman Safi wrote and designed the manuscript. Humaira Shah helped in designing the figure and downloading relevant literature. Dr Rajes Qvist and Professor Gracie Ong reviewed the final version.

\section{Funding/Support}

This work was supported by the bright spark unit of the University of Malaya and UMRG grant no RG528-13HTM.

\section{References}

1. Waheed Y, Safi SZ, Qadri I. Role of Potash Alum in hepatitis C virus transmission at barber's shop. Virol J. 2011;8:211.

2. Safi SZ, Qvist R, Kumar S, Batumalaie K, Ismail IS. Molecular mechanisms of diabetic retinopathy, general preventive strategies, and novel therapeutic targets. Biomed Res Int. 2014;2014:801269.

3. Mehta SH, Brancati FL, Sulkowski MS, Strathdee SA, Szklo M,
Thomas DL. Prevalence of type 2 diabetes mellitus among persons with hepatitis C virus infection in the United States. Ann Intern Med. 2000;133(8):592-9.

4. Antonelli A, Ferri C, Fallahi P, Ferrari SM, Ghinoi A, Rotondi M, et al. Thyroid disorders in chronic hepatitis $C$ virus infection. Thyroid. 2006;16(6):563-72.

5. Sanzone AM, Begue RE. Hepatitis C and arthritis: an update. Infect Dis Clin North Am. 2006;20(4):877-89.

6. Bahtiyar G, Shin JJ, Aytaman A, Sowers JR, McFarlane SI. As sociation of diabetes and hepatitis C infection: epidemiologic evidence and pathophysiologic insights. Curr Diab Rep. 2004;4(3):194-8.

7. Safi SZ, Qvist R, Yan GO, Ismail IS. Differential expression and role of hyperglycemia induced oxidative stress in epigenetic regulation of beta1, beta2 and beta3-adrenergic receptors in retinal endothelial cells. BMC Med Genomics. 2014;7:29.

8. Deng L, Shoji I, Ogawa W, Kaneda S, Soga T, Jiang DP, et al. Hepatitis $\mathrm{C}$ virus infection promotes hepatic gluconeogenesis through an NS5A-mediated, FoxO1-dependent pathway. $J$ Virol. 2011;85(17):8556-68.

9. Safi S, Badshah Y, Waheed Y, Fatima K, Tahir S, Shinwari A, et al. Distribution of hepatitis C virus genotypes, hepatic steatosis and their correlation with clinical and virological factors in Pakistan. Asian Biomed. 2010;4(2):253-62.

10. Batumalaie K, Zaman Safi S, Mohd Yusof K, Shah Ismail I, Devi Sekaran S, Qvist R. Effect of gelam honey on the oxidative stressinduced signaling pathways in pancreatic hamster cells. Int J Endocrinol. 2013;2013:367312.

11. Hsieh MJ, Lan KP, Liu HY, Zhang XZ, Lin YF, Chen TY, et al. Hepatitis $\mathrm{C}$ virus $\mathrm{E} 2$ protein involve in insulin resistance through an impairment of Akt/PKB and GSK3beta signaling in hepatocytes. BMC Gastroenterol. 2012;12:74

12. Aytug S, Reich D, Sapiro LE, Bernstein D, Begum N. Impaired IRS-1/PI3-kinase signaling in patients with HCV: a mechanism for increased prevalence of type 2 diabetes. Hepatology. 2003;38(6):1384-92.

13. Kawaguchi T, Yoshida T, Harada M, Hisamoto T, Nagao Y, Ide T, et al. Hepatitis $\mathrm{C}$ virus down-regulates insulin receptor substrates and 2 through up-regulation of suppressor of cytokine signaling 3. Am J Pathol. 2004;165(5):1499-508.

14. Pazienza V, Clement S, Pugnale P, Conzelman S, Foti M, Mangia $A$, et al. The hepatitis $C$ virus core protein of genotypes $3 a$ and $1 b$ downregulates insulin receptor substrate 1 through genotypespecific mechanisms. Hepatology. 2007;45(5):1164-71.

15. Rui L, Yuan M, Frantz D, Shoelson S, White MF. SOCS-1 and SOCS3 block insulin signaling by ubiquitin-mediated degradation of IRS1 and IRS2.J Biol Chem. 2002;277(44):42394-8.

16. Shintani Y, Fujie H, Miyoshi H, Tsutsumi T, Tsukamoto K, Kimura $S$, et al. Hepatitis $C$ virus infection and diabetes: direct involvement of the virus in the development of insulin resistance. Gastroenterology. 2004;126(3):840-8.

17. Bugianesi E, McCullough AJ, Marchesini G. Insulin resistance: a metabolic pathway to chronic liver disease. Hepatology. 2005;42(5):987-1000.

18. Shoelson SE, Lee J, Yuan M. Inflammation and the IKK beta/I kappa B/NF-kappa B axis in obesity- and diet-induced insulin resistance. Int J Obes Relat Metab Disord. 2003;27 Suppl 3:S49-52.

19. Arkan MC, Hevener AL, Greten FR, Maeda S, Li ZW, Long JM, et al. IKK-beta links inflammation to obesity-induced insulin resistance. Nat Med. 2005;11(2):191-8.

20. Konrad T, Zeuzem S, Toffolo G, Vicini P, Teuber G, Briem D, et al. Severity of HCV-induced liver damage alters glucose homeostasis in noncirrhotic patients with chronic HCV infection. Digestion. 2000;62(1):52-9. 